\title{
Results of treating primary tumours of the trachea by irradiation
}

\author{
A. Y. ROSTOM AND R. L. MORGAN \\ From the Division of Radiotherapy and Oncology, The Royal Marsden Hospital \\ and Institute of Cancer Research, London and Surrey, UK
}

Rostom, A. Y., and Morgan, R. L. (1978). Thorax, 33, 387-393. Results of treating primary tumours of the trachea by irradiation. Forty-four patients presented with primary tumours of the trachea over a 25-year period. Thirty-nine of them were treated by irradiation. Of these, $24(61.5 \%)$ died as a result of their disease while $30 \%$ are either alive and well (4.4-11 years) or have died of intercurrent disease (average four years). Recurrences or metastases when they occurred were in the first two years after diagnosis in all but one patient, who developed local recurrence 3.25 years later. Three patients died of unknown cause (average 5.6 years) after irradiation. Two factors seem to determine the prognosis: the histology and the extent of disease on presentation. Dysphagia without oesophageal involvement carried a grave prognosis.

Primary tumours of the trachea are rare. In a population of 6.8 million in the South Thames cancer region only 18 new cases were registered in 1972 , that is, about 2.6 new cases/million population/year.

In the same year a total of 5168 new cancer cases were registered so that the incidence of primary tracheal tumours is $0.35 \%$ of all cancers in this region (South Thames Cancer Registry Report of the Executive Committee 1975/76 September 1976).

\section{Patients and clinical picture}

During a period of 25 years (1951-75) 44 new patients with primary tracheal tumours were recorded at the Royal Marsden Hospital. We studied their clinical records, and we excluded from this series patients with disease extending to the larynx or the carina and patients with massive mediastinal lymphadenopathy or histologically proved oesophageal infiltration. One patient has been previously reported (Winston, 1958).

AGE AND SEX

Most patients were in the fifth and sixth decade of life (Table 1), and there were about equal numbers of men and women.

\section{SYMPTOMS}

Progressive shortness of breath made worse by exertion was the commonest complaint (Table 2). The average duration of symptoms was three months, and in one patient it was as long as two years. Haemoptysis, usually in the form of bloodstreaked sputum and productive cough, were noted by more than half the patients.

Eleven patients complained of change of voice. One had left vocal cord paralysis and another had sluggish movement of one cord.

Table 1 Age of patients at time of diagnosis and histology for each age group

\begin{tabular}{|c|c|c|c|c|c|c|c|c|}
\hline Age & $\begin{array}{l}\text { Squamous cell } \\
\text { carcinoma }\end{array}$ & $\begin{array}{l}\text { Adenoid cystic } \\
\text { carcinoma }\end{array}$ & Adenocarcinoma & $\begin{array}{l}\text { Oat cell } \\
\text { carcinoma }\end{array}$ & $\begin{array}{l}\text { Undifferentiated } \\
\text { carcinoma }\end{array}$ & $\begin{array}{l}\text { Hodgkin's } \\
\text { disease }\end{array}$ & Chondrosarcoma & No. \\
\hline $\begin{array}{l}30-39 \\
40-49 \\
50-59 \\
60-69 \\
70-79 \\
80-89\end{array}$ & $\begin{array}{r}1 \\
2 \\
12 \\
11 \\
1 \\
1\end{array}$ & $\begin{array}{l}1 \\
1 \\
1\end{array}$ & $\begin{array}{l}1 \\
2 \\
1\end{array}$ & $\begin{array}{l}2 \\
1\end{array}$ & $\begin{array}{l}1 \\
2 \\
1\end{array}$ & 1 & 1 & $\begin{array}{r}2 \\
4 \\
14 \\
19 \\
3 \\
2\end{array}$ \\
\hline Total & 28 & 3 & 4 & 3 & 4 & 1 & 1 & 44 \\
\hline
\end{tabular}


Table 2 Incidence of presenting symptoms and average duration of each

\begin{tabular}{|c|c|c|c|}
\hline \multirow[b]{2}{*}{ Presenting symptoms } & \multicolumn{2}{|c|}{ Patients } & \multirow{2}{*}{$\begin{array}{l}\text { Average } \\
\text { duration }\end{array}$} \\
\hline & No. & $\%$ & \\
\hline $\begin{array}{l}\text { Shortness of breath } \\
\text { Haemoptysis } \\
\text { Cough } \\
\text { Stridor } \\
\text { Change of voice } \\
\text { Loss of weight } \\
\text { Dysphagia } \\
\text { Retrosternal fullness or sensation } \\
\text { of a foreign body in the throat } \\
\text { Fragments of tissues coughed up }\end{array}$ & $\begin{array}{r}36 \\
25 \\
24 \\
12 \\
11 \\
6 \\
5 \\
\\
3 \\
1\end{array}$ & $\begin{array}{l}81 \cdot 8 \\
56 \cdot 8 \\
54 \cdot 5 \\
27 \cdot 2 \\
25 \cdot 0 \\
13 \cdot 6 \\
11 \cdot 3 \\
\\
6 \cdot 8 \\
2 \cdot 2\end{array}$ & $\begin{array}{l}3 \text { months } \\
7 \text { months } \\
7 \cdot 2 \text { months } \\
1 \text { week } \\
4 \text { months }\end{array}$ \\
\hline
\end{tabular}

One patient with adenocarcinoma of the middle third coughed up fragments of tissue, and the histology of this was identical to that of the tracheal tumour.

\section{SIGNS}

Two patients had signs of early superior vena caval obstruction, and both died within a week of presentation. Twelve had stridor, and thyroid enlargement was noted in two patients. One was diagnosed as nodular goitre on subsequent histology, and the other patient was found at necropsy to have thyroid infiltration from squamous cell carcinoma of the upper third of the trachea.

Enlarged paratracheal or deep cervical lymph nodes were felt in three patients. One died 10 days after presentation and the second $\mathbf{1 0}$ months later. The third patient underwent tracheolaryngectomy three months after irradiation and died 26 months later of carcinoma of the right upper lobe bronchus. Wheezes and rhonchi were also noted in 12 of the patients on chest examination.

\section{INVESTIGATIONS}

\section{Radiography}

Chest radiography was performed in all the patients and the result was as follows: no significant abnormality 33, bilateral basal pneumonia 1 , widening of the superior mediastinum 3, paratracheal lymph node enlargement 5 , and narrowing or deviation of the trachea 2.
Tracheal tomography is the most importan $\overrightarrow{\vec{F}^{2}}$ radiological investigation, not only to show the site of the tumour but also to obtain information about the size-particularly the lower extent, the adequacy of the airway, and the presence of extra tracheal extension. The latter information is nof usually obtainable on bronchoscopy, especially in cases with pronounced narrowing of the lumen $\vec{p}$ Tomography was not performed in 14 patients Narrowing of the trachea at the site of the lesior was the most constant finding, while deviation of paratracheal lymph node enlargement was shown in few cases. Tomography was used to assess prow gress in most of the treated patients.

Barium swallow was carried out on 12 casespo Ten showed smooth narrowing and displacement of the barium column by an extrinsic mass. $O P$ these 10 patients, only four complained of dys phagia. The remaining two patients including on who had dysphagia had a normal barium swallow.

Bronchoscopy and biopsy

Bronchoscopy and biopsy is an essential investiga tion in diagnosing primary tracheal tumours since most patients have a normal chest radiograph an the symptoms could be produced by the mord common bronchial tumours. While the site of th lesion was recorded in every case (Table 3 ) it was not always possible to determine the size an extent of the lesion because of severe narrowing of the tracheal lumen. A biopsy specimen wast obtained through the bronchoscope in all cases. In one case with severe stridor endotracheal resection of an adenoid cystic carcinoma was performed before referral for irradiation.

Bronchoscopy after irradiation to assess progres was performed in few patients in this series. Reg gression of tumour was usually seen a month ow two after the end of radiotherapy, but in a case of adenoid cystic carcinoma regression took place over five months.

\section{Oesophagoscopy}

Oesophagoscopy is necessary to exclude advanced cases of oesophageal tumours infiltrating the posv terior wall of the trachea.

Table 3 Distribution of primary tumours of trachea according to site

\begin{tabular}{|c|c|c|c|c|c|c|c|}
\hline Site & $\begin{array}{l}\text { Squamous cell } \\
\text { carcinoma }\end{array}$ & $\begin{array}{l}\text { Adenoid cystic } \\
\text { carcinoma }\end{array}$ & Adenocarcinoma & $\begin{array}{l}\text { Oat cell } \\
\text { carcinoma }\end{array}$ & $\begin{array}{l}\text { Undifferentiated } \\
\text { carcinoma }\end{array}$ & $\begin{array}{l}\text { Hodgkin's } \\
\text { disease }\end{array}$ & Chondrosarcoma \\
\hline $\begin{array}{l}\text { Upper third } \\
\text { Middle third } \\
\text { Lower third }\end{array}$ & $\begin{array}{r}17 \\
4 \\
7\end{array}$ & $\begin{array}{l}2 \\
1\end{array}$ & $\begin{array}{l}2 \\
2\end{array}$ & 3 & $\begin{array}{l}3 \\
1\end{array}$ & 1 & 1 \\
\hline Total & 28 & 3 & 4 & 3 & 4 & 1 & 1 \\
\hline
\end{tabular}


Although it may be difficult in advanced cases to be certain whether the origin is in the trachea or in the oesophagus, the history may help. Patients with oesophageal tumours present with dysphagia while dyspnoea, cough, stridor, and haemoptysis are the early manifestations of tracheal tumours.

Oesophagoscopy was performed only in four patients in this series. There was narrowing with no macroscopic or microscopic evidence of involvement in one patient, and the remaining three patients had normal appearances.

We suggest that this investigation should be performed at the time of bronchoscopy in all patients with suspected tracheal tumour, especially those with dysphagia or changes on the barium swallow.

\section{PATHOLOGY}

\section{Histology}

Histological material was available for all patients, which was examined by more than one pathologist. The histological distribution of the tumours was as follows: squamous cell carcinoma $28(63.6 \%$ ) (well differentiated 1 , moderately differentiated 11 , poorly differentiated 9, and unclassified 7); adenoid cystic carcinoma $3(6.8 \%)$; oat cell carcinoma 3 $(6.8 \%)$; adenocarcinoma $4(9.1 \%)$; undifferentiated carcinoma 4 (9.1\%); Hodgkin's disease-lymphocytic depleted 1; and chondrosarcoma 1.

\section{Metastases}

Table 4 gives details of metastases at the time of death. Eleven out of 12 patients with oat cell carcinoma, undifferentiated carcinoma, adenocarcinoma, and chondrosarcoma developed distant metastases despite the control of local disease in seven of them.

\section{Post-mortem examination}

Necropsy was performed in eight patients. The details of five are given in Table 4 , and the details of the remaining three are as follows. Two patients had poorly differentiated squamous cell carcinoma. One died after four months with progressive local disease. At necropsy the thyroid gland and the right lower deep cervical lymph nodes were infiltrated. The second patient died 10 months after presentation and only local disease was found. The third died of bronchopneumonia 10 months after presentation and at necropsy residual disease and bilateral basal pneumonia were found.

Table 4 Progress of 44 patients with primary tumours of trachea and necropsy findings in five of them

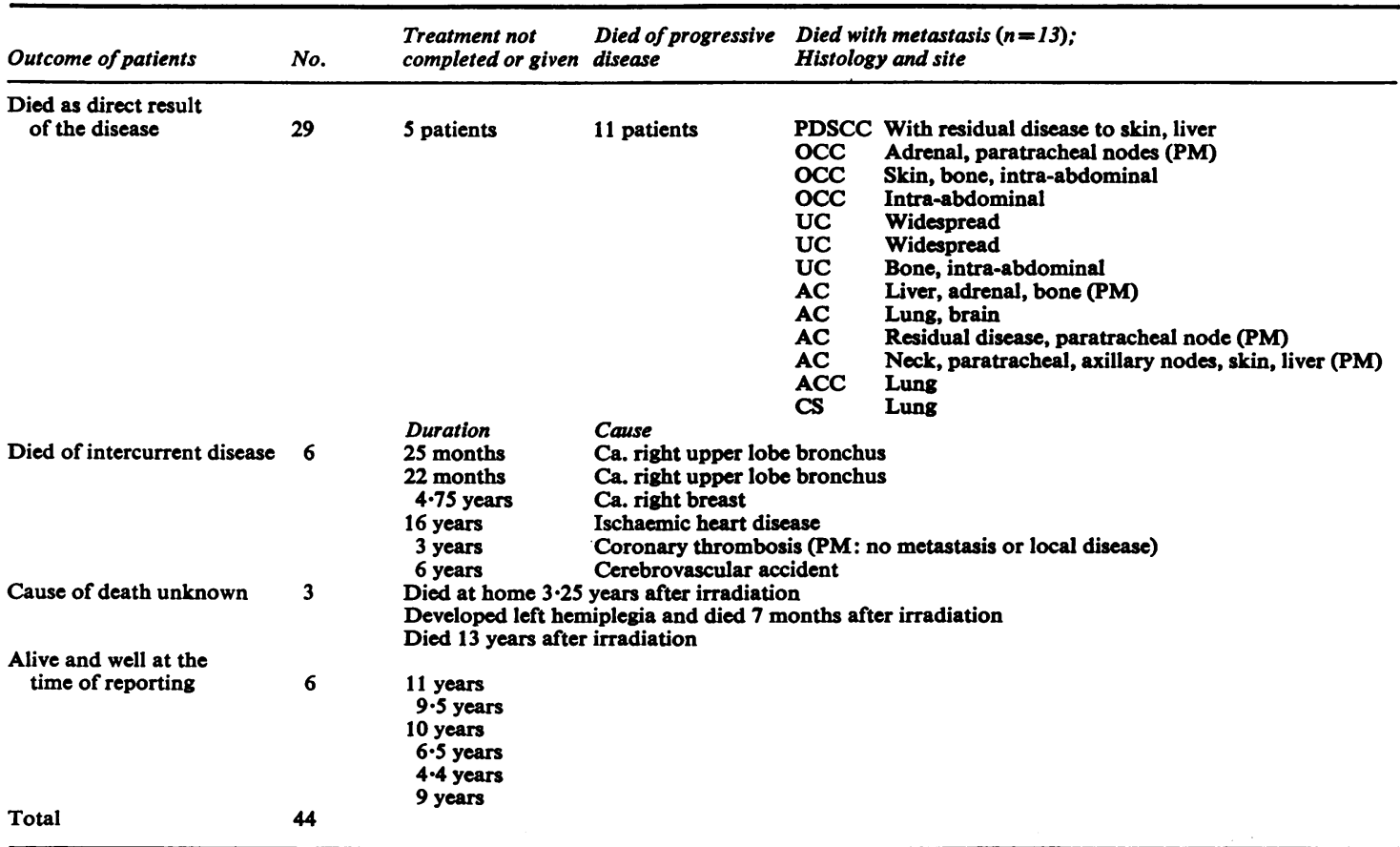

PDSCC $=$ poorly differentiated squamous cell carcinoma; $\mathbf{O C C}=0$ at cell carcinoma; $\mathbf{U C}=$ undifierentiated carcinoma ; $\mathbf{A C}=\mathbf{a d e n o c a r c i n o m a ~}$ ACC = adenoid cystic carcinoma; $C S=$ chondrosarcoma; $\mathbf{P M}=$ post mortem performed. 
Second primary

Hajdu et al. (1970) noted the association of tracheal tumours with tumours in other sites, especially the larynx and lung. Four of the patients in this series developed a second primary tumour, two carcinoma of the bronchus 14 and 25 months from presentation, one carcinoma of the breast 4.8 years, and the fourth carcinoma of the tonsil 19 months from presentation (Winston, 1958).

\section{Treatment}

Thirty-seven patients in this series were treated primarily by irradiation. Two patients were referred for postoperative irradiation after incomplete resection. Four patients were too ill at presentation and only supportive treatment was given, and one patient was referred for follow-up after tracheolaryngectomy. Low emergency tracheostomy was performed in seven of the 12 patients presenting with stridor.

Most of the irradiated patients were treated with ${ }^{80} \mathrm{CO}$ gamma rays, or $2 \mathrm{MeV}$ van-der-Graff or 6
$\mathrm{MeV}$ linear accelerator $X$ rays, usually in a supine $\stackrel{\vec{F}}{\vec{\rho}}$ cast with full extension of the neck. Two anterio wedged oblique fields were usually used. The target volume treated was usually a sloping cylinder starting just below the subglottic regiom of the larynx and extending to the subcarinap region. The anterior and posterior limits of the fields were determined by the findings on the lateral chest radiograph. Because of the variation of tracheal depth from the skin surface in this region three equispaced transverse outlines were taken, one below the superior border of the targetw volume, one along the central axis, and one aboves the inferior border.

With the help of a lateral chest planning radio= graph taken in the treatment position the targe? volume and the spinal cord position are transferred on to each outline. The target volumes of the middle and superior outlines are superimpose $\bar{\phi}$ on to that of the inferior level and the final dosec distribution (see Figure) is achieved at all levelos by placing a lead compensator in the radiation beam to allow for tissue obliquities. By means of

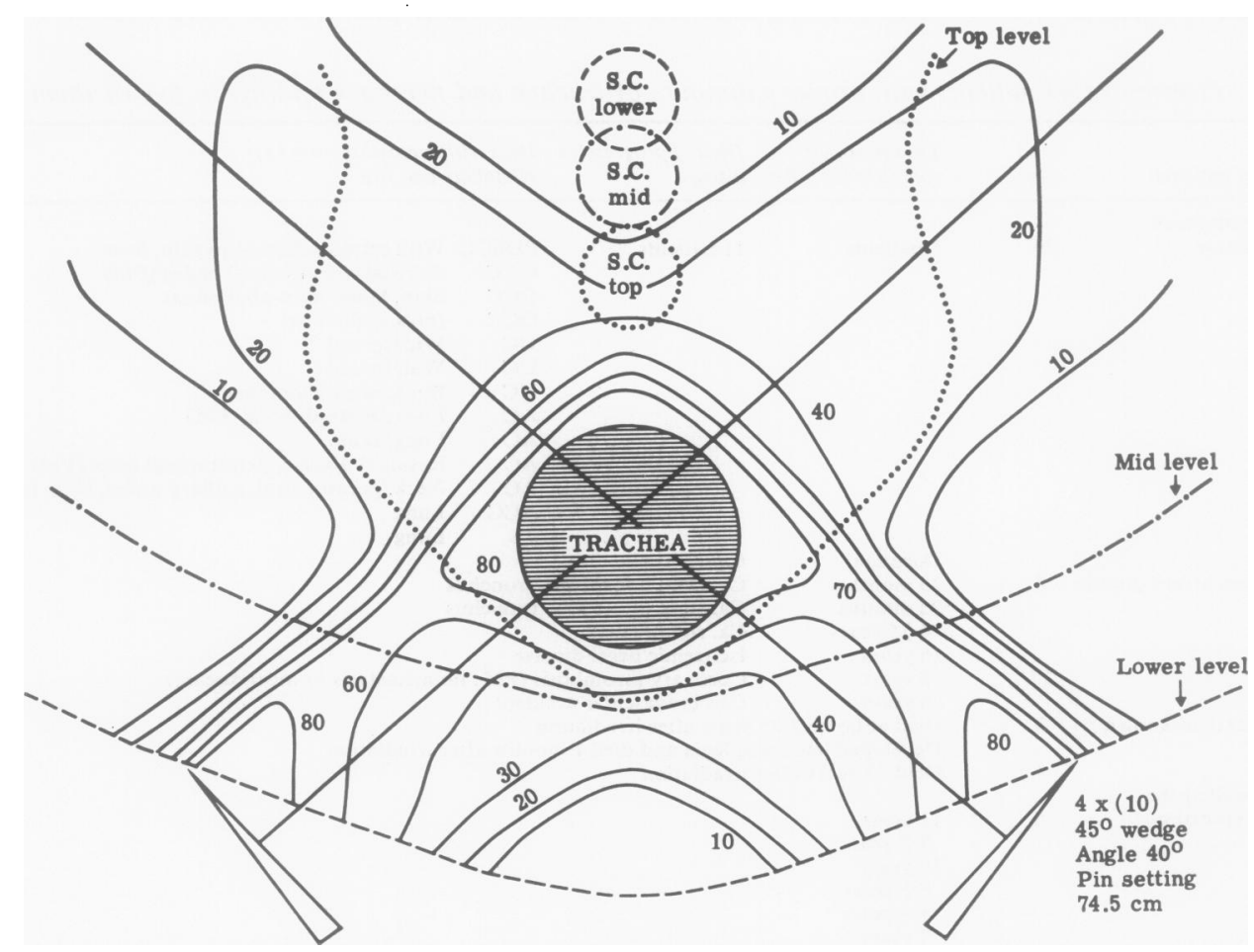

Figure Final dose distribution obtained by use of right and left anterior oblique wedged fields and compensators, showing maximum dose given to target volume 'Trachea'. Ten-40\% of this dose is received by spinal cord ' $S C$ '. 
this technique the dose given to the spinal cord is usually $10-40 \%$ of that given to the target volume.

This technique may not be necessary for the more radiosensitive tumours-for example, oat cell carcinoma or lymphomas-when a lower dose of radiation may be adequate. Anterior and posterior chest fields are usually sufficient.

The tumour dose given was 5000-7000 rad and this was usually given as $1000 \mathrm{rad} /$ week. For various reasons 13 patients out of the total of 44 received doses less than this.

\section{Results}

The patients treated in this series could be divided into two groups - (a) disease limited to the trachea and $(b)$ extratracheal extension.

\section{DISEASE LIMITED TO THE TRACHEA}

Nineteen patients had disease limited to the trachea. Thirteen had squamous cell carcinoma, two had adenocarcinoma, one had an adenoid cystic carcinoma, one an undifferentiated carcinoma, and two oat cell carcinoma. Two patients showed no response to irradiation and died of progressive disease. Five patients developed local recurrence, on average 26 months after irradiation. Two of them had a tracheolaryngectomy and died 22 months and 3.5 years later. Four patients died of intercurrent disease $3,4 \cdot 75,6$, and 16 years after irradiation. One patient died 13 years later of unknown cause. Three patients died of widespread metastases with no evidence of local recurrence. Four patients are alive and well 4.4, 9.5, 10, and 11 years after irradiation.

Radiotherapy eradicated local disease in 11 out of the 19 patients (57.9\%). Even those who developed local recurrence did so on average 26 months after irradiation. This did not interfere with further surgery and longer survival in two patients.

\section{EXTRATRACHEAL EXTENSION}

Twenty patients had extratracheal extension, 12 with squamous cell carcinoma, three undifferentiated carcinoma, two adenocarcinoma, one with adenoid cystic carcinoma, one with Hodgkin's disease, and one with chondrosarcoma.

Two patients showed no response to irradiation and died of progressive disease three and five months later. Six patients showed partial regression of disease. One of them underwent laryngectomy and tracheal resection and died 26 months later from carcinoma of the right upper lobe bronchus. Another patient in this group was treated by repeated radon seed implantation and died from carcinoma of the tonsil 19 months later. The remaining four patients died of progressive disease within six months of presentation. Complete regression of disease was achieved in nine patients. Three of them developed a local recurrence 2,12 , and 39 months after irradiation. One patient died seven months later after a hemiplegia with no evidence of local recurrence.

The effectiveness of radiotherapy was difficult to assess in two more patients. One had a tracheal resection for a chondrosarcoma of the middle third and was referred for postoperative irradiation. He died eight months later with pulmonary metastases. The other, a patient with adenocarcinoma, suddenly died at the beginning of irradiation. Necropsy showed widespread metastases and a massive pulmonary embolism.

Two patients from this group are alive and well. One patient will be discussed in some detail. A 31-year-old man presented with a four-month history of progressive shortness of breath and cough and a one-week history of stridor. Several chest radiographs taken during this period showed no abnormality but four months later irregularity of the right paratracheal region and narrowing of the trachea were noted. Bronchoscopy was performed, and the material obtained showed lymphocyte-depleted Hodgkin's disease. Clinically he had no extrathoracic abnormalities, and his abdominal lymphogram was reported as normal. Irradiation was given through a mantle field to a mid-point dose of $4067 \mathrm{rad}$ in 22 fractions over 36 days. This was well tolerated, and a week later a further $2000 \mathrm{rad}$ in 10 fractions were given to the trachea. $\mathrm{He}$ is alive and well nine years after irradiation. Another patient who had a poorly differentiated squamous cell carcinoma is also alive and well 6.5 years after irradiation.

\section{RADIATION REACTIONS}

Radiation treatment was well tolerated by most patients. Mild dysphagia was the most common complaint, and this developed in 17 patients $(43 \%)$, usually $2 \cdot 5-3.5$ weeks from the start of irradiation. Some degree of dysphagia was unavoidable since the oesophagus was included in the target volume in every case. The dysphagia was treated symptomatically in all cases and subsided a week or two after irradiation. Erythema of the skin was noted in 16 patients $(41 \%)$, and two patients developed moist desquamation. Stridor necessitating low tracheostomy was seen in one patient. Two patients developed tracheal stenosis after irradiation. Tracheostomy was performed and in one a long Jackson tracheostomy tube was inserted. One 
patient developed nausea and vomiting and another hoarseness of the voice.

\section{Discussion}

Primary tumours of the trachea are rare. Because of the non-specific symptoms and signs produced by such tumours they are often overlooked. More than half the patients have advanced disease extending beyond the tracheal confines at presentation.

Most patients in this series had a squamous cell carcinoma $(63.6 \%)$, while only $6.8 \%$ had adenoid cystic carcinoma, which is thought to be the second commonest tumour of the trachea (Salm, 1964). In the published series we found that the incidence of this histological type varied. Houston et al. (1969) found that $38.6 \%$ had such a disease, while only $17 \cdot 4 \%$ of the cases reported by Birt (1970) had adenoid cystic carcinoma and a similar figure was given by Hajdu et al. (1970).

This tumour, however, is slow-growing and is usually treated surgically. Most of the cases referred to us were referred for irradiation and therefore some selection had been made before referral.

In most of the reported series tracheal resection was used as the primary treatment. Our series suggests that resection should be the primary method of treatment for radioresistant lesionsfor example, chondrosarcoma, adenocarcinoma, and perhaps adenoid cystic carcinoma. Irradiation is a good alternative for inoperable cases or those with residual disease. Squamous cell carcinoma of sites other than the trachea may be controlled with irradiation. In this series, of the 24 patients with squamous cell carcinoma who received radical doses of irradiation (6000-7000 rad in 6-7 weeks), 16 had complete regression of the local disease. We think that irradiation should be seriously considered as a first line of treatment for this histological type, especially for patients with disease limited to the trachea.

Primary lymphoma of the trachea and oat cell carcinoma are radiosensitive tumours and may be controlled by moderate doses of radiation. Irradiation with or without endoscopic resection should be used primarily in these cases.

Because of the small number of patients it may be dangerous to draw any conclusions but in this series two factors seem to determine the outcome $-(a)$ the histology of the tumour and $(b)$ the extent of disease on presentation.

Histology-Patients with squamous cell carcinomas and adenoid cystic carcinomas seem to have a better prognosis than those with oat cell carcinoma, undifferentiated carcinoma, adenocar- $\overrightarrow{\vec{S}}$ cinoma, or chondrosarcoma. In the latter group 11 을 out of 12 patients developed metastases despite the 흠 control of local disease in several of them. The $\frac{\bar{s}}{7}$ problem in this group seems to be the later de- $\varnothing$ velopment of metastases after controlling the primary either by irradiation or surgery, and these patients should be considered for the appropriate $\stackrel{\circ}{\circ}$ adjuvant chemotherapy for the particular histo- $\overrightarrow{\vec{\omega}}$ logical type. All the patients in this group have $\stackrel{\sigma}{\omega}$ died as a result of their disease. Of the 31 patients $\overrightarrow{\vec{r}}$ with squamous cell carcinoma and adenoid cystic $\underset{\omega}{\times}$ carcinoma, five are alive and well, six died of $\omega$ intercurrent disease with no signs of local or $\omega$ metastatic disease, and only two died of metastases. $\stackrel{\infty}{v}$

Extent of the disease-Patients were thought to $ᄋ$

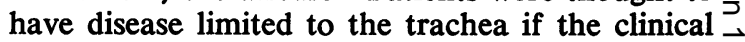
and radiological examination showed no evidence $c$ of spread. Vocal cord paralysis or changes on the barium swallow were taken as an indication of extratracheal extension. A barium swallow was $\oplus$ performed in 12 patients who complained of dysphagia. Ten of them showed smooth narrowing and deviation. Ten of these 12 were dead within 2-19 months, and the only survivor was the patient with stage IIE Hodgkin's disease. The remaining patient had a normal appearance on barium $\stackrel{\varnothing}{\unrhd}$ swallow but died seven months later. Paralysis of $\overrightarrow{\vec{O}}$ one vocal cord was seen in two patients. Both had $\frac{1}{3}$ paratracheal masses and presumably the paralysis was due to infiltration of the recurrent laryngeal nerve.

The results in this series show that patients with disease limited to the trachea have a better prog- $x$ nosis, especially those with tumours of little tend- $\dot{0}$ ency to metastasise-for instance, squamous cell carcinoma. We find that $21 \%$ of this group are alive and well, and the local disease was eradicated by irradiation in $57.9 \%$. Of the patients with 을 extratracheal extension only $10 \%$ are alive, and $\supset$ the disease was controlled in $15 \%$ of them. When local recurrence developed, the disease-free period averaged 26 months in the first group and onlyo 10 months in the second group.

We think that by careful selection of cases $N$ radiation therapy combined with surgery and/or chemotherapy may help to improve survival, especially in patients with advanced lesions or un- $\frac{\widetilde{C}}{\mathbb{Q}}$ favourable histology.

We thank Dr. V. M. Dalley, Dr. M. Lederman, and Professor Sir David Smithers for permission to include details of patients treated under their $\overrightarrow{\mathrm{D}}$ care and Mr. P. Payne, director of the South Thames Cancer Registry, and Miss S. Moore for their help in preparing this paper. 


\section{References}

Birt, B. D. (1970). The management of malignant tracheal neoplasms. Journal of Laryngology and Otology, 84, 723-731.

Hajdu, S. I., Huvos, A. G., Coodner, J. T., Foote, F. W., and Beattie, E. J. (1970). Carcinoma of the trachea. Cancer, 25, 1448-1456.

Houston, H. E., Payne, W. S., Harrison, E. G., and Olsen, A. M. (1969). Primary cancers of the trachea. Archives of Surgery, 99, 132-140.
Salm, R. (1964). Primary carcinoma of the trachea: A review. British Journal of Diseases of the Chest, 58, 61-72.

Winston, P. (1958). Carcinoma of the trachea treated by Radon seed implantation. Journal of Laryngology and Otology, 72, 496-499.

Requests for reprints to: Dr. A. Y. Rostom, Regional Centre of Radiotherapy and Oncology, St. Luke's Hospital, Warren Road, Guildford, Surrey GU1 3NT. 